REVISTA DE DERECHO UNED, núm. 5, 2009

\title{
VISIÓN PSICOCRIMINOLÓGICA DEL DOLO Y LA IMPUTABILIDAD (II)
}

\author{
ALEJANDRO Solís ESPINOZA \\ Doctor en Derecho y psicólogo. Profesor de Criminología \\ en la Pontificia Universidad Católica de Perú y en la Universidad \\ Nacional Mayor de San Marcos
}

\section{ASPECTOS PSICOLÓGICOS EN LA «CAPACIDAD DE CULPABILIDAD«}

\subsection{La «capacidad de culpabilidad» o imputabilidad}

Existen diversas nociones al respecto y en relación al nombre, por ejemplo Mir Puir (33) emplea el término imputación personal, que es seguido por otros penalistas. Según J. Cerezo (14), en la culpabilidad se examina, si se le puede reprochar al sujeto, la realización de la acción u omisión típica y antijurídica, y que esto sólo es posible si tal persona, en la situación concreta en que se hallaba, podía obrar de otro modo, de acuerdo con el ordenamiento jurídico. Sin embargo, pueden existir acciones típicas y antijurídicas no culpables, cuando concurra alguna causa de inimputabilidad o de inculpabilidad, pero no hay acción culpable que no sea típica y antijurídica, secuencia irreal según el modelo lógico abstracto imaginado por la dogmática alemana. En nuestro medio, Luis Miguel Bramont-Arias (10), considera que la culpabilidad es la posibilidad de atribuir un hecho desvalorado a su autor, y que la esencia de la misma se halla en el reproche que se le formula por su acción opuesta a lo estipulado por el ordenamiento jurídico. Para Villavicencio, la «culpabilidad es imputar responsabilidad por un injusto a un individuo en base a la exigibilidad en un ámbito comunicativo, 
en atención a condicionamientos reconoscibles en una determinada práctica social» $(63)$.

La naturaleza de la capacidad psíquica de culpabilidad o imputabilidad del actor, es materia de debate en el ámbito jurídico penal, no existiendo consenso a lo largo de su desarrollo histórico. Jiménez de Asúa (30) decía, siguiendo a Mayer, que la imputabilidad era la posibilidad para obrar según el justo conocimiento del deber, condicionada por la salud mental y el desarrollo del autor. Para Jorge Frías (22) se concebía a la imputabilidad como la "capacidad personal de reprochabilidad éticosocial», en función de un conjunto de condiciones biopsicológicas de la concreta personalidad del agente, para comprender lo injusto o antijurídico del hecho y para dirigir las acciones conforme a esa comprensión. Ideas similares planteaba A. Reyes (43), y anotaba que esa capacidad depende de condiciones psico-físicas, relacionadas con la madurez mental y con la normalidad fisiológica y psicológica del individuo, y en ciertos casos con la valoración que el sujeto (indígena) es capaz de hacer respecto a las normas culturales y legales de la sociedad.

Dentro del finalismo, Eugenio Zaffaroni considera que «la imputabilidad es la capacidad psíquica de ser sujeto de reproche, compuesta de la capacidad de comprender la antijuricidad de la conducta y la de adecuar la misma a esa comprensión»(69), aunque posteriormente, bajo la influencia de la criminología crítica asume una visión cuestionadora del poder punitivo y de su plano jurídico al que considera asentada sobre una ficción. Enrique Bacigalupo, también bajo la orientación finalista, denomina capacidad de motivación o capacidad de culpabilidad a la imputabilidad, y señala que «la capacidad de motivación es de naturaleza eminentemente jurídica: no debe confundirse, por lo tanto, con una cuestión médica o psiquiátrica, aunque sea necesario determinar algunos aspectos mediante conceptos médicos»(?) (03). No obstante que diversos autores prefieren la denominación de capacidad de motivación, dicho término no es ajeno a la vida mental, porque en la psicología actual la noción de motivación constituye un constructo complejo, que incluye condiciones muy diversas y dentro de este contexto no se puede hablar de conducta humana sin motivación, la misma que está ligada a procesos psicofisiológicos y otras variables, sobre lo que no existe un consenso conceptual (07)(17). Por tanto no nos parece consistente la idea de que la capacidad de motivación sea de naturaleza «eminentemente jurídica»(?), cuyo contenido conceptual esté librado a la creación argumentativa y cambiante de los juristas, que elaboran nociones de imputabilidad que se refieren a estados de capacidad psicológica, pero sin considerar los conceptos psicológicos o psiquiátri- 
cos, basado en razonamientos metafísicos (psicología esotérica). Berdugo y otros (06), señalan también que la imputabilidad supone la capacidad de motivación del autor por la norma penal, lo que requiere averiguar, si el sujeto estaba en situación de comprender la ilicitud del hecho o de actuar conforme a esa comprensión.

Desde la psiquiatría también se han planteado diversos conceptos, entre ellos Serpa (50) considera que la imputabilidad es un conjunto de condiciones que la ley exige, para que a una persona se le pueda atribuir un hecho punible, y que tales condiciones son a veces de orden psiquiátrico, psicológico y socio cultural, que le permiten comprender la ilicitud de su conducta. Por su parte, el psiquiatra forense Vicente Cabello (12) sigue ideas similares a Serpa, aunque centrando la imputabilidad, sólo en las condiciones psicológicas de la persona.

De acuerdo a la perspectiva jurídica o la visión psicológica, han surgido en la doctrina penal diversas tendencias relativas a la imputabilidad:

\section{Tendencia Psicológica pura}

2. Tendencia Psiquiátrica sola (biológica según algunos), y

3. Tendencia Jurídico-Psicológico-psiquiátrica (Mixta)

De las tendencias nombradas, el diferenciar entre una psiquiátrica y otra psicológica no es tan real, ya que si bien la psiquiatría tiene que ver con la patología mental, esta temática de la anormalidad mental constituye un ámbito de la psicopatología, que es un capítulo de la psicología en general, por lo que se debería decir más bien tendencia psicopatológica o psicológica. Asimismo creemos que es más congruente considerar la segunda tendencia como «biológica pura» (?), que estaría orientada a tomar en cuenta los aspectos de la madurez biológica y la patología orgánica concomitantes a los trastornos psíquicos o de conducta, y no identificarla como psiquiátrica sola.

En suma, la orientación mixta, bio-psico-jurídica es más integral, sin dejar de anotar que lo predominante para la valoración de la imputabilidad es la dimensión psicológica, por lo que la fórmula podría ser tan sólo Psicológico-Jurídica.

\subsection{La inimputabilidad o incapacidad de culpabilidad}

Para el derecho penal, la ausencia de imputabilidad exime de responsabilidad penal al agente de un hecho antijurídico, existiendo múltiples causales de inimputabilidad en las legislaciones vigentes, 
aunque existen ciertos criterios básicos dominantes con diferencias específicas según cada legislación.

El autor colombiano Agudelo (01), consideraba que la inimputabilidad es la incapacidad para regular la conducta según las exigencias del derecho por causas de inmadurez psicológica o trastorno mental. A. Reyes, por su parte decía, que la inimputabilidad es la incapacidad para conocer y comprender la antijuricidad de su conducta o para determinarse de acuerdo con esa comprensión, debido a fallas de carácter psicosomático o sociocultural, y que «se evidencian en el desarrollo mental deficitario, inmaduro o senil, en trastornos biosíquicos permanentes o transitorios, en dificultades de acomodamiento sociocultural o en obnubilación de la conciencia» (43). En este caso Reyes tuvo como fuente de análisis el código penal colombiano de 1980.

Según la doctrina actual, la inimputabilidad requiere que en el sujeto se encuentren afectados dos elementos: a) La capacidad de comprender lo injusto; y b) la capacidad de actuar conforme a esa comprensión, debido a ciertas anomalías. Elementos que se acogen en el artículo 20 inciso $1 .^{\circ}$ del C.P. peruano, agregando que se halle afectado gravemente su concepto de la realidad.

En la legislación podemos ver algunas tendencias. El código penal peruano de 1924 indicaba que estaban exentos de pena, según el artículo 85 e inciso $1^{\circ}$. "El que comete el hecho punible en estado de enfermedad mental, de idiotez, o de una grave alteración de la conciencia y no posee en el momento de obrar la facultad de apreciar el carácter delictuoso de su acto o de determinarse...».

El Código Penal Federal de México (02) del año 1931, estipula en artículo 15, lo siguiente:

«Art. 15.-El delito se excluye cuando:

II. Al momento de realizar el hecho típico, el agente no tenga la capacidad de comprender el carácter ilícito de aquel o de conducirse con esa comprensión, en virtud de padecer trastorno mental o desarrollo intelectual retardado, a no ser que el agente hubiera preordenado su trastorno mental dolosa o culposamente, en cuyo caso responderá por el resultado típico...»

El código penal colombiano del año 2000, en el numeral 33 señala también al respecto:

Art. 33. -... «Es inimputable quien en el momento de ejecutar la conducta típica y antijurídica, no tuviere la capacidad de comprender su ilicitud o de determinarse de acuerdo con esa comprensión, por inmadurez sicológica, trastorno mental, diversidad sociocultural o estados similares». 
No será inimputable el agente que hubiere preordenado su trastorno mental.

Los menores de dieciocho años estarán sometidos al sistema de responsabilidad penal juvenil.

Las dos últimos textos son similares al indicar el Trastorno Mental y la inmadurez psicológica o desarrollo intelectual retardado como condiciones de inimputabilidad

El Código penal peruano de 1991 establece en el artículo 20, incisos $1 .^{\circ}$ y $2 .^{\circ}$ lo siguiente:

«Art. 20.-Está exento de responsabilidad penal:

1. ${ }^{\circ}$ El que por anomalía psíquica, grave alteración de la conciencia o por sufrir alteraciones en la percepción, que afectan gravemente su concepto de la realidad, no posea la facultad de comprender el carácter delictuoso de su acto o para determinarse según esta comprensión.

2. ${ }^{\circ}$ El menor de 18 años.

El actual Código Penal español de 1995, estipula sobre este punto lo siguiente:

Cuadro 1. Inimputabilidad

\begin{tabular}{|l|l|l|l|}
\hline $\begin{array}{l}\text { Codigo Penal } \\
\text { Peruano 1924 }\end{array}$ & $\begin{array}{l}\text { Codigo Penal } \\
\text { Peruano 1991 }\end{array}$ & $\begin{array}{l}\text { Codigo Penal } \\
\text { Español 1995 }\end{array}$ & $\begin{array}{c}\text { Codigo Penal } \\
\text { Colombiano 2000 }\end{array}$ \\
\hline $\begin{array}{l}\text { - Enfermedad } \\
\text { mental }\end{array}$ & - Anomalía & $\begin{array}{l}\text { Anomalía o } \\
\text { Alteración. } \\
\text { Trastorno }\end{array}$ & $\begin{array}{l}\text { Idiotez psíquica Psíquica } \\
\text { (trastorno mental transito- } \\
\text { rio) }\end{array}$ \\
\hline $\begin{array}{l}\text { - Grave alte- } \\
\text { ración }\end{array}$ & $\begin{array}{l}\text { - Grave alte- } \\
\text { ración }\end{array}$ & $\begin{array}{l}\text { Estados de intoxicación de la conciencia } \\
\text { de la conciencia plena por alcohol, droga } \\
\text { Mental tóxica, estupefacientes, sustancias } \\
\text { psicotropas u otras... o se halle bajo síndro- } \\
\text { me de abstinencia }\end{array}$ \\
\hline $\begin{array}{l}\text { - Alteraciones en la percep- } \\
\text { ción desde el nacimiento o } \\
\text { infancia }\end{array}$ & Alteraciones en la percepción \\
\hline - Inmadurez psicológica \\
\hline - Diversidad sociocultural \\
\hline $\begin{array}{l}\text { - Menor de } \\
18 \text { años de } \\
\text { edad }\end{array}$ & $\begin{array}{l}\text { Menor de } \\
18 \text { años de } \\
\text { edad }\end{array}$ & - Menor de \\
18 años & Menor de 18 años \\
\hline
\end{tabular}


"Artículo 19. Los menores de dieciocho años no serán responsables criminalmente con arreglo a este Código».

«Artículo 20. Están exentos de responsabilidad criminal»:

1. El que a tiempo de cometer la infracción penal, a causa de cualquier anomalía o alteración psíquica, no pueda comprender la ilicitud del hecho o de actuar conforme a esa comprensión.

El trastorno mental transitorio no eximirá de pena cuando hubiese sido provocado por el sujeto con el propósito de cometer el delito o hubiera previsto o debido prever su comisión.

2. El que a tiempo de cometer la infracción penal se halle en estado de intoxicación plena por el consumo de bebidas alcohólicas, drogas tóxicas, estupefacientes, sustancias psicotrópicas u otras que produzcan efectos análogos, siempre que no haya sido buscado con el propósito de cometerla o no se hubiese previsto o debido prever su comisión, o se halle bajo la influencia de un síndrome de abstinencia, a causa de su dependencia de tales sustancias, que le impida comprender la ilicitud del hecho o actuar conforme a esa comprensión.

3. El que, por sufrir alteraciones en la percepción desde el nacimiento o desde la infancia, tenga alterada gravemente la conciencia de la realidad.

En el esquema comparativo (Cuadro N. ${ }^{\circ}$ 1) de nuestra legislación penal del 24 y la vigente, así como del C.P. colombiano y el español, se anotan algunas semejanzas como diferencias sobre las condiciones de inimputabilidad. Sin embargo haremos el análisis de tales condiciones, según los criterios de nuestro C.P. del 91, con algunas referencias a las demás legislaciones mencionadas.

\subsubsection{Inimputabilidad por anomalia psiquica}

Antes de revisar los casos de inimputabilidad por «anomalía psíquica» que se estipula en nuestro código penal de 1991, debemos precisar que tal denominación, si bien es un término que se maneja dentro del ámbito de la psiquiatría y la psicopatología actuales, plantea no obstante algunas dudas y dificultades debido a la diversa clasificación psiquiátrica del siglo pasado. Sin embargo, tendremos como fuente a la última Clasificación Internacional de Enfermedades (CIE-10), que se revisa decenalmente, en la que se incluye la clasificación relativa a los Trastornos Mentales (36)(54)(66). Aunque es importante mencionar también a la clasificación norteamericana (DSM) (39), seguida por diversos psiquiatras. 
El nombre general que se emplea para lo que antes se encuadraba bajo el rótulo genérico de enfermedades mentales, es el de Trastornos Mentales, con el agregado de «y Conductuales» hecha por la CIE-10, junto a un reajuste de la clasificación anterior, adoptando una codificación alfanumérica para cada trastorno mental, considerando ONCE grupos que pueden incluir 100 categorías de trastornos o anomalías psíquicas con códigos de una letra y dos dígitos (F00 hasta F99), cada una de las cuales contiene a su vez síndromes más específicos (F00.0, F00.1, etc.).

En la psiquiatría actual el término «trastorno mental» es equivalente en parte, aunque de contenido más lato, a la de «enfermedad mental» que hoy no es muy usada como lo fue en las primeras décadas del siglo pasado. Al respecto, los psiquiatras hasta la primera mitad del siglo XX, fueron partidarios de considerar como enfermedad mental sólo los casos en que había una base orgánica morbosa detrás de tal alteración, sobre todo bajo la influencia de K. Schneider (47). Otros por su parte, sólo incluían bajo tal rubro a las psicosis (alienación), tal como H. Delgado (18), siguiendo también a Schneider, excluyendo otros trastornos como el retraso mental (oligofrenia), trastornos de personalidad (psicopatías), neurosis, entre otras anomalías, que según Frías, no eran «enfermedades mentales genuinas sino meros estados anormales del psiquismo» (22). Sin embargo aún hoy, algunos hablan de enfermedad abarcando a todos los problemas mentales (53)(65), no obstante que el término trastorno mental de uso actual desde hace más de sesenta años, incluye a todas las anomalías mentales, desde las más graves a las menos graves, orgánicas y no orgánicas, las de breve duración hasta las que tienden a la cronicidad.

En los años 70, Serpa en su Tratado de psiquiatría forense de 1979, consideraba equivalentes los términos trastorno mental y enfermedad mental, cuando decía que «las enfermedades o trastornos mentales se han dividido en varios grupos...»(49). Sin embargo, las clasificaciones actuales sólo emplean la denominación de trastorno mental, lo que se aprecia en la CIE-9 y CIE-10 de la OMS y también en la DSM-IV norteamericana de 1994. Similar nombre acogen algunos códigos penales, como la colombiana de 1980 y la nueva del 2000, así como el Código Penal Federal de México de 1931 reformado, que ya hemos citado. Al respecto, Irma Amuchátegui al comentar la ley mexicana dice que el «trastorno mental incluye cualquier alteración o mal funcionamiento de las facultades psíquicas, siempre y cuando impidan al agente comprender el carácter ilícito del hecho o conducirse acorde con esa comprensión. Puede ser 
transitorio o permanente, por ingestión de alguna sustancia nociva o por un proceso patológico interno» $(\mathbf{0 2})$ ».

Nuestro Código Penal de 1991, optó también por un término lato: Anomalía psíquica, lo mismo que el Código penal español de 1995 que usa una denominación alternativa "o alteración psíquica», términos afines al empleado en las clasificaciones psiquiátricas actuales, que es el de trastorno mental. Sin embargo, nuestro legislador aún mantiene en rubro aparte a la "grave alteración de la conciencia», como un problema diferente, cuando realmente es una especie de la anomalía psíquica o trastorno mental. Igualmente, el texto español citado, en una redacción no muy feliz, en el segundo párrafo del primer inciso hace mención al «trastorno mental transitorio» preordenado, pero que debería entenderse como una especie o variedad de anomalía psíquica, ya que se halla dentro del inciso "anomalía o alteración psíquica», y no como una entidad independiente de tal anomalía, como si ocurría en los textos penales anteriores. Asimismo, el Código español considera en inciso aparte los «estados de intoxicación plena» y el «síndrome de abstinencia», como si fueran diferentes a la "anomalía psíquica». Por ello creemos que el Código Penal Colombiano y la ley mexicana, son en este aspecto más adecuados, al emplear el término genérico trastorno mental, de uso actual en la nosología psiquiátrica, y no haber explicitado las especies de anomalías que generan inimputabilidad..

Similar parecer al criterio que adoptamos, siguen algunos psiquiatras forenses como A. Langeluddeke (31), y el ya citado Serpa que en un artículo del año de 1982, posterior a su Tratado de 1972, al comentar sobre la inimputabilidad en el Código Penal Colombiano de 1980, se inclinaba por entender la denominación de trastorno mental, en sentido amplio, y comprendía no sólo a las »enfermedades mentales propiamente dichas, sino algunas otras anormalidades psíquicas menos severas tales como las neurosis, las graves alteraciones de la conciencia, de las emociones y ciertos trastornos de la personalidad...» (50), sin embargo en una obra posterior (1994), al comentar el «trastorno mental transitorio», del artículo 33 del C.P. colombiano del 80 sigue un parecer no muy claro y en contradicción con la psiquiatría actual (51). Según Roberto Solórzano (1990), también psiquiatra forense, el «trastorno mental es un término genérico que incluye toda la patología mental, desde los trastornos de la personalidad, pasando por la neurosis y psicosis, hasta las conductas compulsivas» (58), aunque erróneamente excluye al retraso mental porque considera que no es una "enfermedad», siguiendo una idea superada de la psiquiatría de inicios del siglo XX, entrando en contradicción con su primera afirmación.- 
Retomando la ley peruana que habla de anomalía psíquica, esta debe interpretarse en sentido equivalente al de trastorno mental, pero restringida a las anomalías que afectan gravemente el concepto de la realidad, y que no permiten comprender el carácter delictuoso del acto para determinarse según tal apreciación, lo que significa que si el imputado padece un «trastorno mental» que no ocasiona tales limitaciones, no tendrá importancia para alegar la inimputabilidad. Por ello veremos las anomalías que tienen relevancia como condiciones de inculpabilidad, destacando sobre todo las psicosis, el retardo mental y algunas otras anomalías mentales. Analizaremos asimismo la llamada "grave alteración de la conciencia», que el legislador peruano la sigue manteniendo aparte diferenciándola de la «anomalía psíquica» que es más genérica.

En este punto, Terradillos siguiendo a Muñoz Conde dice que en la anomalía psíquica «tienen cabida no sólo las enfermedades mentales, como neurosis o psicopatías, sino también «aquellos defectos o alteraciones del proceso de socialización relevantes en la determinación de la inimputabilidad de un individuo, aunque no sean estrictamente reconducibles al concepto de enfermedad mental» (M. Conde) (61). En principio, por la buena intención de la doctrina penal, no se puede ampliar la noción de anomalía psíquica hasta abarcar problemas de socialización, siguiendo interpretaciones basadas en una libre argumentación. Sin embargo, esto no es óbice, si la realidad lo amerita, para que el defecto o carencia de socialización se incluya como otra causal de inculpabilidad, pero no dentro de anomalía psíquica, ya que llevaría a reconstruir la noción de inimputablidad, lo que probablemente generaría también una controversia metafísica, como el afirmar basado en la «ciencia jurídica», "que la imputabilidad es un concepto jurídico, no médico o psiquiátrico». Sin embargo esta discusión es parte del bizantinismo de la doctrina penal en la que no entraremos, salvo en señalar la incongruencia de mezclar carencia social con anomalía mental.

1.2.1.1. Psicosis e Inimputabilidad: La psicosis es un trastorno mental que ha recibido una nomenclatura variada por las diversas leyes y códigos penales a lo largo de la historia, habiéndose empleado los términos de "furia», "vesania», «insania», «locura», "alienación mental», «enajenación mental», «demencia» y a veces «enfermedad mental», que son términos antiguos y en cierto modo equivalentes al término psicosis de la psiquiatría del siglo $\mathrm{XX}$, aunque también esta última denominación tiende a ser reemplazada en los últimos tiempos. 
Las Psicosis que describen las clasificaciones psiquiátricas abarcan varios tipos o categorías, y fueron ubicadas en dos grandes grupos por la CIE-9: Psicosis orgánicas y Otras psicosis. Para la CIE 9 (OMS-75), la psicosis es un trastorno «en el cual el menoscabo de la función mental ha alcanzado un grado tal que interfiere marcadamente con la comprensión (introspección) y la capacidad para afrontar algunas demandas ordinarias de la vida o para mantener un adecuado contacto con la realidad» (36). Además hay que precisar que el número de las psicosis es grande, y sólo veremos en una presentación sumaria a las más importantes en el campo forense. Precisamente, según la experiencia psiquiátrica penal, las psicosis son las causas de inimputabilidad mas frecuentes; aunque en la última CIE10 (OMS-93) el término psicosis tiende a ser dejado de lado y sólo se le mantiene en el trastorno cuyo código es F23 y en alguna otra anomalía mental.

a. Las psicosis orgánicas: Son síndromes, según la CIE-9, «en los cuales se presenta un deterioro de la orientación, de la memoria, de la comprensión, de la habilidad para el cálculo, de la capacidad para el aprendizaje y del juicio(..). También puede hallarse superficialidad o labilidad del afecto o una persistente alteración del ánimo, mengua de las normas éticas, aparición de nuevos rasgos de la personalidad o exageración de las preexistentes» (36). En estos casos es un factor orgánico lo que condiciona la psicosis por deterioro cerebral, procesos tóxicos u otras anomalías somáticas. Parte de tales psicosis han sido reclasificadas, por la CIE-10, dentro del grupo de Trastornos Mentales Orgánicos, Incluidos los Sintomáticos (códigos F00 a F09). Este grupo de anomalías abarca a su vez diversas categorías como las siguientes:

1. Demencia en la enfermedad de Alzheimer (F00): Se presenta en la ancianidad, debido a una degeneración cerebral de causa desconocida. Abarca diversas especies de trastornos, como la Demencia en la enfermedad de Alzheimer de Inicio Precoz (F00.0); Demencia en la enfermedad de Alzheimer de Inicio Tardío (F00.1), entre otras, en las que el psicótico orgánico senil o presenil, debido a su demencia asociada a la enfermedad de Alzheimer, es una persona inimputable debido al deterioro mental que le impide su comprensión de la realidad en caso de infringir la ley penal.

2. Demencia Vascular (F01): Llamada demencia arteriosclerótica en la clasificación anterior, en este problema mental la demencia es consecuencia de los infartos del tejido cerebral. El inicio del trastorno tiene lugar en edad avanzada e incluye diversas modalidades como los siguientes: Demencia vascular de inicio agudo (F01.0), De- 
mencia multi-infarto (F01.1), Demencia vascular subcortical (F01.2), y otras variedades.

3. Demencia en enfermedades clasificadas en otro lugar (F02): Abarca varios cuadros como la demencia en la enfermedad de Pick (F02.0) que se inicia generalmente entre los 50 y 60 años de edad, por una atrofia selectiva de los lóbulos frontales y temporales del cerebro. Demencia en la enfermedad de Creutzfeldt-Jakobs (F02.1); Demencia en la enfermedad de Parkinson (F02.3); Demencia en la infección por HIV (F02.4); Demencia en otras enfermedades específicas clasificadas en otro lugar (F02.8), como la lipidosis cerebral, epilepsia, P.G.P., deficiencia de vitamina B12, degeneración hepatolenticular, etc.

4. Demencia sin especificación (F03).

5. Síndrome Amnésico orgánico no inducido por alcohol u otras sustancias psicotropas (F04).

6. Delirium no inducido por alcohol u otras sustancias psicotropas (F05). En este caso «Se trata de un síndrome cerebral orgánico que carece de una etiología específica, caracterizado por la presencia simultánea de trastornos de la conciencia y atención, de la percepción, del pensamiento, de la memoria, de la psicomotilidad, de las emociones y del ciclo sueño-vigilia» (35). Es un cuadro transitorio que puede durar hasta seis meses, generalmente se pueden recuperar en cuatro semanas o menos, y se presenta en cualquier edad, pero con más frecuencia después de los 60 años de edad.

7. Otros trastornos mentales debido a lesión o disfunción cerebral o a enfermedad somática (F06): Abarca trastornos originados por alteraciones encefálicas debidas a enfermedad cerebral primaria, a enfermedad sistémica o de otra naturaleza, que afectan secundariamente al cerebro o por una sustancia tóxica exógena excluyendo al alcohol y las sustancias psicotropas. Hay una enfermedad médica (somática): sea neurológica (epilepsia, enfermedad de huntington etc.), endocrina (hiper e hipotiroidismo, hipofunción suprarrenal), metabólica (hipoglucemia, hipoxia, etc.), etc., que pueden originar los síntomas psicóticos. Son importantes el F06.0 Alucinosis orgánica, caracterizado por alucinaciones persistentes y F06.2 Trastorno de ideas delirantes (esquizofrenoforme) orgánico, con predominio de ideas delirantes persistentes o recurrentes.

Parte de los dos últimos cuadros genéricos (F05 y F06) se denominaban «Psicosis orgánicas transitorias» en la CIE-9, e incluyen trastornos que dada su breve duración o transitoriedad, fueron con- 
sideradas como variedades de «grave alteración de la conciencia» o «trastorno mental transitorio», en la legislación penal y por la psiquiatría forense de la primera mitad del siglo XX.

b. Inimputabilidad por trastorno mental debido al consumo de sustancias psicotropas: La CIE-10 ha hecho un cambio sustancial en la clasificación de los trastornos mentales inducidos por el consumo de alcohol y las drogas que seguía la CIE-9, concentrando bajo un solo grupo a todas las anomalías producidas por el uso de tales sustancias, desde las agudas hasta las psicóticas, bajo el rubro de Trastornos Mentales y del comportamiento debidos al consumo de sustancias psicotropas (F10 a F19), en el que existen diversas categorías de trastornos.

1. Trastornos mentales y del comportamiento debidos al consumo de alcohol (F10), que incluye:

- Intoxicación Aguda (F10.0): Que abarca diversas alteraciones, como la no complicada (F10.00), en este caso de acuerdo al grado de alcoholemia, si llega a ebriedad absoluta (1.5 a 2.5 $\mathrm{g} / \mathrm{l})$ y hasta el 4to. periodo (2.5 a $3.5 \mathrm{~g} / \mathrm{l})$, será inimputable, salvo los casos estipulados por ley. Asimismo la Intoxicación patológica (F10.07) o «ebriedad patológica», que se clasificó como una variedad de Psicosis alcohólica por la CIE-9, puede llevar a la eximencia penal. Este trastorno se consideró una «grave alteración de la conciencia» por la psiquiatría forense de la primera mitad del siglo XX.

- Síndrome de dependencia (F10.2).

- Síndrome de abstinencia (F10.3).

- . Síndrome de abstinencia con delirium (F10.4), trastorno que incluye al "delirium tremens» que es un estado tóxico-confusional, que se inicia luego de interrumpir el consumo de alcohol en personas dependientes o alcohólicas, caracterizado por «obnubilación de la conciencia y estado confusional, alucinaciones e ilusiones vividas en cualquier modalidad sensorial y temblor intenso» (35). En la CIE-9 se le clasificó como Psicosis alcohólica», y también en la primera mitad del siglo pasado se le consideró como una "grave alteración de la conciencia».

- Trastorno psicótico (F10.5): trastorno que se desencadena por el consumo crónico de bebidas alcohólicas, como la «celotipia alcohólica», «alucinosis alcohólica», "paranoia alcohólica», etc. 
2. Trastornos mentales y del comportamiento por consumo de opioídes (F11), cannabinoide (F12), Sedantes e hipnóticos (F13), cocaína (F14), etc., incluye las variedades siguientes:

- Intoxicación Aguda (F1x.0), en función al grado de intoxicación.

- Síndrome de Dependencia (F1x.2).

- Síndrome de Abstinencia (F1x.3).

- Síndrome de Abstinencia con delirium (F1x.4).

- Trastorno psicótico (F1x.5): Las psicosis debidas a drogas son sobre todo la del tipo anfetamínico, barbitúricos, LSD. También se dan reacciones psicóticas por el consumo de la cocaína y de la marihuana. En estos casos, el trastorno puede ser causal de inimputabilidad del procesado por el acto ilícito cometido en tal estado. Algunas psicosis debidas a drogas, junto con las alcohólicas, por ser transitorias, fueron consideradas variedades de la "grave alteración de la conciencia» $\mathrm{o}$ "trastorno mental transitorio» (T.M.T.), por la psiquiatría forense de la primera mitad del siglo XX, por lo que insistimos que inadecuadamente se le mantiene como una entidad aparte de la anomalía psíquica en nuestro actual código penal. Asimismo también nos parece inconsistente la legislación española, que ubica alguno de estos cuadros como entidad aparte de la anomalía o alteración psíquica.

c. Inimputabilidad en casos de "Esquizofrenia, Trastorno Esquizotípico y Trastornos de Ideas Delirantes»(F20-F29): Este nombre de la CIE-10 reemplazó a la denominación de Psicosis Esquizofrénica y Estados Paranoides que empleó la CIE-9, y que estaba incluido dentro del grupo de las Otras Psicosis (no orgánicas). Este grupo presenta diversas modalidades:

1. La esquizofrenia(F20): Abarca al grupo de «psicosis que presenta un desorden fundamental de la personalidad, una distorsión del pensamiento, con frecuencia un sentimiento de estar controlado por fuerzas ajenas, ideas delirantes que pueden ser extravagantes, alteraciones de la percepción, afecto anormal sin relación con la situación real y autismo», entre otros síntomas. Incluye varios tipos, como la Esquizofrenia paranoide (F20.0), Esquizofrenia hebefrénica (F20.1), Esquizofrenia tipo catatónica (F20.2), Esquizofrenia indiferenciada (F20.3), etc.

Dada la gravedad de esta psicosis, que ocasiona pérdida del sentido de la realidad y distorsiones del pensamiento, del afecto, la per- 
cepción, entre otras, la inimputabilidad del esquizofrénico es evidente. Sin embargo no siempre este trastorno se presenta lo suficientemente claro, sobre todo en sus fases iniciales. Asimismo es la psicosis que mas ocasiona inimputabilidad en los diversos países del mundo, sobre todo la esquizofrenia paranoide, lo que también se observa en nuestro medio, hecho que también señala Víctor Prado (41), y que en nuestra indagación personal también hemos constatado, alcanzando la mayor incidencia respecto a otros trastornos mentales.

2. Trastorno esquizotípico (F21).

3. Trastornos de ideas delirantes persistentes (F22): Antes llamada paranoia. Incluye una variedad de trastornos en los que las características clínicas destacadas o únicas son las ideas delirantes, sobre un único tema delirante o de un grupo de ideas, que pueden ser de persecución, hipocondríaca, de grandeza, de litigio, entre otros. Dada tal sintomatología, personas con este trastorno tienen cierto riesgo de cometer un hecho ilícito, en cuyo caso serían inimputables.

4. Trastornos psicóticos agudos y transitorios (F23) etc.

d. Inimputabilidad en los Trastornos del Humor (F30-F39): En este caso la CIE-10 ha efectuado también un cambio sustancial en la clasificación respecto a la CIE-9, al incluir en este grupo todos los trastornos del humor o afectivos, desde los leves y no psicóticos hasta aquellos psicóticos. De este modo incluye diversos trastornos.

1. Episodio maníaco (F30) que abarca varios cuadros, entre ellos la manía con síntomas psicóticos (F30.2).

2. Trastorno bipolar (F31) en el que destaca el Trastorno bipolar, episodio actual maníaco con síntomas psicóticos (F31.2), y el Trastorno bipolar, episodio depresivo grave con síntomas psicóticos (F31.5).

3. Episodios depresivos (F32), en el que sobresale el Episodio depresivo grave con síntomas psicóticos (F32.3).

4. Trastorno depresivo recurrente (F33), sobre todo el trastorno depresivo recurrente, episodio actual grave con síntomas psicóticos.

La CIE-9 clasificó en grupo aparte los cuadros graves que acabamos de indicar, bajo el rubro de Psicosis Afectivas (296), antes llamadas psicosis maníaco-depresivas, como trastornos en los que hay una alteración grave del ánimo (compuesta de depresión y ansiedad, o que también se expresa como alborozo y excitación), «acompañado de uno o más de los sintomas y signos siguientes: ideas delirantes, 
perplejidad, perturbación de la actitud hacia si mismo, trastornos de la percepción y del comportamiento...» (36). Distinguiendo el tipo maniaco (296.0), tipo depresivo (296.1), circular fase maniaca (296.2), circular fase depresiva (296.3). Estas psicosis pueden originar diversos problemas psicológico-forenses, sobre todo si el hecho delictivo ocurre en un periodo donde no existe brote maníaco o brote depresivo. Pero en este como en cualquier trastorno mental, lo que importa es el estado de anomalía psíquica durante el evento delictivo. Al respecto Serpa dice que hay psicosis periódicas como la «maniaco-depresiva, que cursan con largos periodos asintomáticos y no puede, en sana lógica, considerarse en estado de enajenación mental a un maniaco-depresivo durante las fases de salud compensada, asintomática, o sea, cuando no está en las fases de excitación maniaca o de depresión melancólica» (50).

Además de las psicosis, otras anomalías mentales como las neurosis, trastornos de personalidad, entre otras, pueden llegar a producir inimputabilidad en ciertos casos, no obstante que la neurosis y los trastornos de personalidad no tienen la gravedad de las psicosis.

1.2.1.2. Neurosis e Inimputabilidad: La CIE-10 la denomina Trastornos neuróticos secundarios a situaciones estresantes y somatomorfos (F40 a F49). En la mayoría de casos no constituye una anomalía suficiente para avalar la inimputabilidad, aunque Berdugo y otros interpretan que la neurosis al ser catalogadas como trastorno mental sería «una causa de inimputabilidad en sentido estricto» (06). Solo algunas neurosis pueden llegar a niveles intensos de alteración mental, que pueden ocasionar la eximencia completa del sujeto:

a. Trastornos de Ansiedad Fóbica (F40): En ciertos casos los estados de fobia son muy severos en algunos pacientes, y pueden condicionar situaciones de inimputabilidad según las circunstancias. Por ejemplo, en la agorafobia (F40.0) caracterizada por un temor extremo a los lugares abiertos y en ciertos casos temor a las multitudes, la dificultad para escapar a un lugar seguro, sobre todo a la casa del paciente, podría dar lugar al riesgo de cometer daños o lesiones en ese trance, por lo que podría ser declarado inimputable. Sin embargo, esta persona no estaría exenta de pena en caso de robos, estafas, violaciones, ni de otro delito. Tampoco de daños o lesiones si los realiza cuando no se halla con ataques de fobia. Algunas agorafobias pueden manifestarse con trastorno de pánico (F40.01).

b. Otros trastornos de Ansiedad (F41): Incluye varios síndromes específicos, sobre todo el trastorno de pánico (Ansiedad paroxística 
episódica) (F41.0), caracterizado por crisis constantes de grave ansiedad(pánico), no limitada a cierta circunstancia particular. Frecuentemente se acompaña de palpitaciones repentinas, dolor precordial, sensación de asfixia, mareo o vértigo y sensación de irrealidad (despersonalización o desrealización). Asimismo puede manifestarse un temor secundario a morir, perder el control o enloquecer, que lo impulsa a salir o escapar del lugar donde se halla Las crisis duran algunos minutos, pero a veces pueden ser más prolongadas, y en el caso de ser un motivo de inimputabilidad, tendrá que evaluarse casuísticamente en función del delito, pero por ejemplo este neurótico no podría alegar inimputabilidad en el caso de violación sexual basado en este trastorno mental, tampoco si realiza cualquier delito cuando no esta en situaciones de pánico.

c. Trastornos disociativos (de conversión)(F44): Presentan en común «la pérdida parcial o completa de la integración normal entre ciertos recuerdos del pasado, la conciencia de la propia identidad, ciertas sensaciones inmediatas y el control de los movimientos corporales» (35). A veces pueden desencadenar en algunos pacientes «estados crepusculares» que pueden alterar su capacidad y sentido de la realidad. En este grupo se pueden diferenciar:

- La Amnesia disociativa (F44.0).

- La fuga disociativa (F44.1).

- El estupor disociativo (F44.2).

- Trastornos de trance y de posesión (F44.3).

1.2.1.3. Trastorno específico de personalidad (psicopatía) e inimputabilidad: Abarca más de diez variedades de trastornos específicos (F60 a F69). Se discute si estas anomalías, conocidas décadas atrás como psicopatías, pueden ser causas de inimputabilidad, aunque la argumentación empleada a su favor es a veces obsoleta, como por ejemplo el planteamiento de Carlos Irrisari (28). Sin embargo, Zaffaroni al igual que Berdugo y otros, consideran también que el «psicópata» es inimputable, porque entienden equívocadamente que es un «enfermo mental». La enfermedad mental significaba un trastorno grave para la psiquiatría de fines del siglo XIX y la primera mitad del siglo pasado, sin embargo las llamadas «psicopatías» en esa época no eran incluidas en ese grupo. Hoy la psiquiatría los considera una variedad de trastorno mental, término más lato que «enfermedad mental», pero no todos los trastornos mentales generan inimputabilidad. No obstante, tampoco podría afirmarse una responsabilidad plena, como lo veremos más adelante. 
De los diversos trastornos específicos de personalidad, el llamado Trastorno de la personalidad de tipo impulsivo (F60.30), antes denominado "psicópata explosivo», podría generar en ciertos casos la inimputabilidad del agente. Freedman y otros (21) dicen que esta personalidad puede ser afable, entusiasta y parecer bien adaptada. Sin embargo, cuando se enfrentan con situaciones de conflicto o claros contratiempos, puede reaccionar de manera violenta, con explosiones de cólera, a veces hasta el punto de agresiones físicas o suicidio. Es una persona con frecuentes explosiones de violencia. Kurt Schneider, prácticamente lo identificaba con la «reacción en corto circuito» (40), descrita por Kretschmer, la misma que prácticamente no tuvo acogida en la actual literatura psiquiátrica, pero que alguno penalistas aun la acogen como una grave alteración de la conciencia.

1.2.1.4. Inimputabilidad en el retraso mental (F70-F79): Este trastorno no está señalado específicamente en el Código Penal de 1991, y creemos que acertadamente, ya que es parte de la anomalía psíquica o trastorno mental, como ya lo hemos anotado. Al respecto, desde hace medio siglo atrás el término retraso mental reemplazó al de oligofrenia, anomalía que los italianos, bajo influencia de Sancte de Santis (15), llamaban frenastenia. Sin embargo, algunos psiquiatras forenses aún emplean el término obsoleto, como se aprecia en los tratados de Bonnet, Cabello, Solórzano, Langeluddeke, entre otros. Esto se observa también en algunos penalistas (03)(06)(33)(44) que todavía usan tal denominación antigua, así como por Alfonso Reyes (43), quien erróneamente lo ubicaba dentro de las psicosis. En la psicología actual se entiende que el retraso mental es un trastorno caracterizado por un déficit en el desarrollo intelectual, con diversos niveles de deficiencia, cuyas causas son varias, y que se manifiesta desde el nacimiento o los primeros meses de vida.

Los niveles de este retardo son cuatro, diferenciándose según varios criterios, entre ellos el del cociente intelectual (C.I.) que se mide por alguna prueba o test de inteligencia; el desarrollo psicomotor (en la primera infancia); el adiestramiento escolar; así como el grado de adecuación social. Sin embargo no todos los niveles de retraso mental condicionan la inimputabilidad, debido a que presentan diferencias importantes, en las que por ejemplo, según la mayoría de autores, el grado leve o discreto (31) no justificaría una plena inimputabilidad. Como ya lo señalamos, el C.I. es un criterio que sirve para delimitar cuantitativamente los niveles del retraso mental, cuya equivalencia con los grados de la antigua denominación de oligofrenia (57), se aprecia en el cuadro N. ${ }^{\circ} 2$. 
Cuadro 2. Oligofrenia y Retraso mental

\section{RETRASO MENTAL OLIGOFRENIA}

1. Retraso mental leve o discreto: - Debilidad mental: CI 50-70 CI 50-69

2. Retraso mental moderado: CI 35-49 - Imbecilidad

3. Retraso mental grave: CI 25-49 - CI 20-34

4. Retraso mental profundo: - Idiocia: CI menos de 20 CI menos de 25

La persona con retraso mental Leve, teniendo en cuenta su deficiencia intelectual no muy severa, su adecuación social y de acuerdo al nivel de escolaridad logrado, no siempre es inimputable pleno, salvo que viva en un ambiente de severa deprivación social que contribuya en ahondar su déficit intelectual, lo que tendría que valorarse en el caso concreto. Al respecto Osvaldo Tieghi, usando la nomenclatura antigua afirma que la «debilidad mental, por si, no equivale a insuficiencia significativa, como causal de inimputabilidad» (62). En sentido opuesto se pronuncia Jaime Naquira (34), que empleando la misma denominación y basado en criterios jurídicos de igualdad, así como el considerar la ley mas benigna para el reo, el in dubio pro reo, entre otros, plantea que el «débil mental» debe ser considerado inimputable en todos los casos, ya que si su capacidad mental es inferior a la de una persona de 16 años y siendo inimputables los menores de edad, el «débil mental» también lo debe ser, argumento que es muy discutible. Sin embargo consideramos que es parcialmente imputable, como ya lo hemos dicho, idea que ha seguido la jurisprudencia. Sólo en ciertas condiciones, según cada caso concreto, podría avalarse la inimputabilidad, criterio que en cierto modo también plantea Frías Caballero (22).

Las personas con retraso mental moderado, grave y profundo, tienen un déficit muy serio de capacidad intelectual y de comprensión en general, y requieren de ayuda para alcanzar a satisfacer sus necesidades vitales. Estos casos de retardo justifican la inimputabilidad del actor por el hecho antijurídico que cometa.

\subsubsection{Inimputabilidad $y$ "grave alteracion de la conciencia»}

En el código penal de 1991 se mantiene la «Grave alteración de la conciencia» (G.A.C), que también había sido acogido en el código de 1924, como una eximente aparte de la anomalía psíquica. Sin em- 
bargo, según la psicopatología actual, la anomalía psíquica o trastorno mental abarca a todos los tipos de alteración psicológica, desde los más graves hasta los menos severos, permanentes o transitorios, así como los condicionados por factores orgánicos o los de índole socio-emocional, no teniendo razón de ser el de mantener actualmente tal diferencia.

La "grave alteración de la conciencia» tiene su antecedente en la psiquiatría de fines del siglo XIX que se hallaba carente de sistematización, comparado con el desarrollo actual, al lado de un derecho penal incipiente. En tal contexto, según comentarios de W. Weygandt (64) y la referencia de Langeluddeke, el parágrafo 51 del Código Penal alemán de 1871 había acogido la figura del «estado de inconciencia», cuyo texto decía: "No hay una acción punible cuando el autor, en el momento de la ejecución del hecho, se encuentra en estado de inconsciencia o de perturbación patológica de la actividad mental» (31). En dicha época, Richard Von Krafft Ebing (1840-1903), influyó decisivamente, con su obra Medicina legal de los alienados (1885) en dos volúmenes, en cuyo primer tomo: «Medicina legal de los alienados en derecho penal», analizó la capacidad de imputación en los casos de "estados de inconsciencia», trastornos que debido a su fugacidad, gravedad de la perturbación y falta de memoria posterior, se distinguía de la perturbación patológica o «enfermedad mental» crónica, idea aceptada por la psiquiatría de la época que no tenía consolidada una nosología consensual, lo que recién ocurrió en su primera versión a fines del siglo XIX e inicios del XX con Kraepelin. Por ello, algunos estudiosos, como Roberto Ciafardo, considera que Krafft-Ebbing «fue el primer autor que, bajo el nombre de "estados de inconsciencia patológica», agrupó las perturbaciones psíquicas de diversa naturaleza, más o menos pasajeras, que hasta entonces habían sido estudiadas por la psicopatología médicolegal con la denominación de «locuras transitorias» (16). Mas tarde el nombre "estado de inconciencia patológica» es reemplazado por «perturbación de la conciencia». Al respecto, Langelüddeke anota «que quien está inconsciente no puede obrar y, en consecuencia, no puede realizar una acción criminal» (31), asimismo afirma que con la nueva expresión no se introdujo ningún cambio real, porque la inconsciencia se interpretó como turbación de la conciencia. Dichas ideas se trasuntan en el Anteproyecto Suizo de Código Penal de 1915, bajo la denominación de "grave alteración de la conciencia», la que sirvió de fuente a nuestra legislación de 1924 y que se mantiene en el texto del Código penal de 1991.

Zaffaroni anota también, refiriéndose a los proyectos de Código penal argentino de fines del siglo XIX e inicios del XX, que «en cier- 
to momento, de todos los proyectos desaparece la voz de «inconsciencia», siendo reemplazada por el de «trastorno mental transitorio involuntario» o por la "grave perturbación de la conciencia» (68). Sin embargo el «estado de inconsciencia» se acogió en el artículo 34, inciso $1 .^{\circ}$ del C.P. argentino. En otros cuerpos legales se optó por la denominación de «trastorno mental transitorio», cuyo texto habría sido por primera vez regulado en el código penal soviético de 1927, según Enrique Henríquez (24), y en 1931 por el Código Penal mexicano en su Art. 15, que habló de estado de inconciencia determinado por ciertas condiciones o por trastorno mental involuntario de carácter patológico y transitorio, y luego por el Código penal español de 1932, cuya fórmula del «trastorno mental transitorio» (T.M.T.) fue redactada por Jiménez de Asúa y el psiquiatra Sanchis Banus, para superar también el empleo del término «inconciencia», sin embargo Sanchiz Banus consideraba que la inconciencia patológica suponía una alienación mental de cierto tipo, esto es ser transitoria (08), idea no acogida ni comprendida por los juristas españoles. El artículo 8o. de dicho Código decía:

«Están exentos de responsabilidad criminal: $10^{\circ}$ El enajenado y el que se halle en situación de trastorno mental transitorio, a no ser que éste haya sido buscado de propósito».

El Código de Defensa Social cubano de 1932 también estipuló, en su artículo 34, que eran inimputables: «el enajenado y el que se halle al tiempo de cometer el delito en estado de trastorno mental, aunque fuere de carácter transitorio».El código penal colombiano de 1936, en su artículo 29 hacía referencia a la «enajenación mental, grave anomalía psíquica o intoxicación crónica por alcohol u otras sustancias». El Código Penal Tipo Latinoamericano dice: «No es imputable quien, en el momento de la acción u omisión, y por causa de enfermedad mental, de desarrollo psíquico incompleto o retardado, o de grave perturbación de la conciencia, no tuviere la capacidad». Como se aprecia de los textos citados, la tendencia dominante en parte del siglo pasado, siguió el criterio nacido en el siglo XIX, de que la «enajenación mental» o enfermedad mental, era diferente a la G.A.C. o T.M.T. Sin embargo estas últimas «anomalías» no figuran en las clasificaciones psiquiátricas del siglo $\mathrm{XX}$, y constituyen entidades inexistentes en el campo médico, como también lo señaló Luís Carlos Pérez (38). No obstante, se mantuvieron en los códigos penales del siglo XX con un contenido ambiguo y variado, según el criterio de cada psiquiatra forense o el pensamiento de los penalistas que lo interpretaban y aun comentan (25). Al respecto, en España la jurisprudencia adoptó el criterio de señalarle una base patológica, escasa duración y 
término de la alteración sin dejar huella. Sobre el particular, dice Antonio Doval Pais, la «difícil delimitación del trastorno mental transitorio, sobre todo en cuanto a su etiología y efectos, obligó a dotar de contenido a una figura que carecía de reconocimiento científico bajo aquel rótulo» (19), idea con la que concordamos.

En nuestro Código penal, además de los aspectos psicopatológicos que supone dicha GAC, se adicionan otras condiciones, como el no poseer «la facultad de comprender el carácter delictuoso de su acto o para determinarse según esta comprensión». En este caso, siguiendo el criterio antiguo, se entendería que abarca una variedad de alteraciones psíquicas breves, que ocasionan distorsión y perturbación de la conciencia o de la lucidez mental en forma transitoria, y que por ello se justifica la inimputabilidad del agente que se halla en tal estado durante el evento delictivo. En tanto que las «enfermedades mentales» se decía que eran anomalías con base patológica, idea inmersa en la legislación de 1924 y que se mantiene igual en el Código Penal de 1991 (37), siguiendo la tradición de legislaciones de raigambre antigua, no obstante que la psiquiatría, desde mediados del siglo pasado, incluye en la denominación genérica de trastorno mental a todas las anomalías mentales, sea cual fuere su etiología y duración. Los cultores del derecho penal en este caso, han permanecido anquilosados en las ideas de fines del siglo XIX, desconociendo el avance de la psicopatología.

A fines del siglo XIX, Krafft-Ebing presentó una clasificación de los estados de inconciencia patológica (09), en los que incluyó los cuadros genéricos siguientes:

1. Estados anormales del sueño y del ensueño.

2. Estados de inconciencia patológica por alteración circulatoria aguda del cerebro.

3. Estados de inconciencia patológica por sustancias tóxicas.

4. Estados de inconciencia patológica por procesos patológicos exclusivamente físicos.

5. Estados de inconciencia patológica por estados pasionales.

6. Estados de inconciencia patológica en las mujeres de parto y pos parto (estado puerperal).

Cada estado de inconciencia abarcaba, a su vez, una variedad de anomalías específicas. En Latinoamérica siguieron tal criterio diversos psiquiatras forenses, como E. Henríquez (1955), quien incluía entre los casos de «trastorno mental transitorio» (T.M.T), a diversas anomalías mentales (24): 
Asimismo dentro de esta tendencia, pero ya más moderna, Bonnet (1964), consideró que todos los casos de T.M.T. eran patológicos, pudiendo obedecer a causas endógenas o exógenas. Ademas diferenció entre T.M.T. completo y T.M.T. incompleto, afirmando que el primer caso se trataba «de un estado de alienación mental brevísimo» (08), acercándose al criterio actual, incluyendo diversas entidades. El T.M.T. incompleto estaba representado por los «estados crepusculares», cuadros mentales en los que existen resabios de atención, memoria, conciencia, como una «semialienación».

En estudio posterior, Serpa (1979) decía respecto a la grave anomalía psíquica acogida en el código penal colombiano de 1936, que en ella «no deben incluirse las enfermedades mentales o sicosis (que son mas bien enajenación mental o alienación)», idea que seguía un punto de vista obsoleto y ajeno a la clasificación psiquiátrica internacional ya vigente en esos años. Aunque luego anotaba «en qué enfermedades mentales o trastornos psíquicos podría invocar la grave anomalía psíquica», lo que resultaba incongruente con su primera apreciación, considerando entre otras, a la «embriaguez patológica», que como se puede advertir era clasificada ya desde varias décadas atrás como una forma de Psicosis alcohólica; «los actos impulsivos; "las explosiones o actos explosivos en corto circuito» (personalidad explosiva); $y$ «las crisis agudas de angustia», tales como el pánico.

Alfonso Reyes (43) desde la visión de penal, distinguió entre T.M.T. con secuela patológica y sin secuela patológica. El primero incluía algunas formas leves de psicosis y de psicopatías de origen traumático, neurosis histérica, ciertos estados delirantes, con los que prácticamente aludía a determinados trastornos mentales. El T.M.T. sin secuela patológica se caracterizaba porque la perturbación "presente en el momento del acto delictivo, desaparecía sin dejar huellas clínicamente perceptibles. En este grupo consideraba a la sugestión hipnótica, el sonambulismo, la embriaguez del sueño, las alteraciones emocionales agudas o estados febriles de ciertas enfermedades somáticas. De este T.M.T. sin secuela que indica Reyes, la sugestión hipnótica y el sonambulismo, inicialmente considerados por Krafft Ebing, realmente no son causas de inimputabilidad y en rarísimos casos condicionarían a lo más ausencias de acción. Al respecto, ya a inicios del siglo XX el psiquiatra forense Weygandt decía que si bien esto era aceptable teóricamente, "no tiene en la práctica ninguna trascendencia» (64). Más tarde para Langeluddeke, casos de delito bajo hipnosis eran "extremadamente raros que carecen de importancia práctica» (31); por su parte Serpa afirma que «en cuanto a los posi- 
bles delitos cometidos en estado de sonambulismo o de perturbación del sueño son una hipótesis meramente académica que hasta donde sabemos no se presenta en la práctica» (49); similar idea plantea Ciafardo (15). Los demás casos enumerados por Reyes, según la intensidad de la anomalía, caen también dentro de los Trastornos mentales que hemos glosado.

Eugenio Zaffaroni, decía años atrás (1982) que algunos casos de TMT «que son verdaderas causas de inimputabilidad», a título de ejemplo, eran los siguientes: Intoxicación aguda por alcohol o enervantes, ebriedad del sueño, ciertos estados oníricos, psicosis posteriores al parto, entre otros, que ya hemos comentado. Esteban Righi, refiriéndose al arcaico término de "estado de inconsciencia» del art. 34 inciso $1 .^{\circ}$ del C.P. argentino, considera que incluye «los estados crepusculares, el sueño, la fiebre, los desmayos o la sugestión hipnótica» (44). Realmente resulta increíble que en pleno siglo XXI se considere que el sueño, la fiebre, los desmayos y la sugestión hipnótica sean causales de inimputabilidad. Los estados crepusculares son variedades de trastorno mental que se pueden presentar en epilépticos o en neurosis disociativa.

En síntesis, del recuento de las alteraciones que se han venido señalando como expresiones de G.A.C., consideramos que prácticamente todas ellas están descritas con mayor precisión dentro de la clasificación psiquiátrica contemporánea, como modalidades de trastornos mentales o anomalías psíquicas. Al respecto, como resumen apreciamos que tradicionalmente se han considerado como formas de G.A.C. o TMT, a las siguientes anomalías mentales:

- Delirium tremens (Hoy tipo de trastorno mental por alcohól).

- Ebriedad patológica (Otro tipo de trastorno mental alcohólico).

- Delirio debido a drogas (Hoy trastorno mental debido a drogas).

- Síndrome de abstinencia (Hoy trastorno mental por alcohól o debido a drogas).

- Estado crepuscular epiléptico (Hoy tipo de psicosis orgánica...).

- Delirio febril o toxiinfeccioso (Hoy trastorno mental orgánico).

- Sonambulismo (Hoy un tipo de trastorno no orgánico del sueño), etc.

Por ello es redundante aceptarlas como entidades "patológicas» diferentes a los trastornos mentales o anomalías psíquicas, siendo 
erróneo mantenerlos en las leyes penales del siglo XXI. Al respecto, Vicente Cabello (1982), refiriéndose a la legislación argentina, también consideraba desacertado el uso en psiquiatría forense del término trastorno mental transitorio por las siguientes razones: Crea «al margen de las ciencias psiquiátricas una categoría taxonómica sin respaldo clínico ni psicopatológico, abarcando todas las entidades morbosas de evolución aguda o sobreaguda cuyo ordenamiento es del dominio exclusivo de la psiquiatría» (13). Sin embargo, paradójicamente en otro capítulo acepta la existencia de la «grave alteración de la conciencia», pero prácticamente como síntoma de otros trastornos, por lo que el mismo argumento crítico señalado para el TMT sería aplicable para la GAC que dicho autor acepta como otra entidad, no obstante que son términos equivalentes por el contenido que se les atribuye.

\subsubsection{Inimputabilidad y alteraciones de la percepcion}

El Código vigente incluye una causal de inimputablidad que puede tener interpretaciones diversas, por una redacción no muy feliz, cuando dice que está exento de responsabilidad, el que por sufrir alteraciones en la percepción, que afectan gravemente su concepto de la realidad, no posea la facultad de comprender el carácter delictuoso de su acto o para determinarse según esta comprensión. De tal texto, según una interpretación gramatical se puede inferir que tales alteraciones son las ilusiones y sobre todo las alucinaciones visuales, auditivas, olfatorias, entre otras. Sin embargo, como las alucinaciones son síntomas de algunos trastornos mentales y si ellas afectan gravemente el concepto de la realidad, y alteran la comprensión del sujeto, estaríamos ante procesos psicóticos como algunos cuadros de esquizofrenia, psicosis alcohólica, psicosis debida a drogas alucinógenas tipo LSD, entre otras que están incluidas en el rubro de anomalía psíquica. Si esta es la voluntad del legislador o el «espíritu de la ley», se trataría de una causal de inimputabilidad reiterativa y sin razón, al separarse un síntoma particular de alguno de los trastornos mencionados, para considerarlo eximente autónoma.

Sin embargo, al hacer una interpretación histórica podemos ver que el legislador peruano la ha tomado del artículo 8. ${ }^{\circ}, 3$ (Ley 8 de 25 de junio de 1983) del Código Penal Español hoy derogado, que decía: «El que por sufrir alteraciones en la percepción desde el nacimiento o desde la infancia, tenga alterada gravemente la conciencia de la realidad»; la misma que fue una redacción que reemplazó a otra que se re- 
fería al «sordomudo de nacimiento o desde la infancia, que carezca en absoluto de instrucción»; texto que fue materia de crítica por diversos penalistas españoles, como Cobos y Vives que la consideraron una eximente excesivamente abierta (16). El codificador peruano, probablemente para no parecer que hacía una copia fiel, eliminó la referencia a la alteración desde el nacimiento o la infancia, y generó un texto confuso. Por ello se puede entender que dicha causal acogida en nuestro código, se refiere a tal problema, vinculado al «sordomudo de nacimiento o desde la infancia». Al respecto, la sordomudez no origina necesariamente un estado de inimputabilidad, ya que una persona con esta carencia o deficiencia sensorial (y no realmente alteración de la percepción) (?), generalmente no tiene dificultades en su compresión de la realidad y menos si reciben educación especial, y hasta pueden alcanzar un buen desarrollo en el arte o la ciencia, no obstante que el texto español le adicionaba el «que carezca en absoluto de instrucción». Además, si estas personas tuvieran un trastorno mental, dicha anomalía sería la causa de inimputabilidad, pero no por el hecho de ser sordomudo.

La persona carente de audición o limitado sensorial auditivo es muda porque es sorda o anacúsica de nacimiento y por tanto no aprende a hablar, pero con educación especial pueden desarrollar el habla. La sordera o anacusia además es de diverso tipos, y son los grados severo y profundo de nacimiento (23), los que condicionan la sordomudez. Asimismo, según M. ${ }^{a}$ Suria la «inteligencia innata media del deficiente auditivo es igual a la de los niños que oyen. Igualmente pueden presentarse deficientes mentales entre los sordos que entre los oyentes; pero nunca será más deficiente un sordo por el hecho de serlo» (59). Por ello, como decía Bacigalupo (03), la nueva redacción de la ley española era tan superflua como la anterior y que no requería un tratamiento específico, aconsejando su derogación. Además la participación delictiva del sordomudo no es importante, al respecto el psiquiatra forense Langeluddeke dice: «yo no he tenido que informar acerca de ningún sordomudo durante mis treinta y cinco años de práctica forense» (31). Sin embargo el nuevo Código Penal español de 1995, mantiene dicho texto, como ya lo hemos visto más arriba, aunque Bacigalupo reitera que sería aconsejable derogar tal disposición (05).

La redacción de nuestro Código es muy genérica, y más oscura que su fuente española, que no obstante ser cuestionada, por lo menos de su texto se infiere que hace referencia a una carencia sensorial presente desde la infancia o el nacimiento, de lo que puede colegirse que alude a sordos, ciegos, anósmicos, entre otros, aunque como 
anota tímidamente Mir Puig, «no parece que afecten específicamente a la "percepción" » (33). Si nuestros codificadores consideran que el caso del sordomudo e incluso la ceguera, avalan el ser incluidos como causas de inimputabilidad, un texto centrado en tal propósito hubiera sido el de señalar: «Por padecer de limitación o carencia sensorial auditiva o visual, desde el nacimiento o la infancia, que afecte gravemente su comprensión de la realidad...», y no hablar erróneamente de alteraciones de la percepción. Asimismo, si el anacúsico tuviera rasgos psicopatológicos, se hallaría dentro de la anomalía psíquica, conforme a la perspectiva actual de la nosología psiquiátrica. Sin embargo, la doctrina penal basada en la argumentación, por lo menos en España, la está llenando de un contenido más amplio, basado en la imaginación de los interpretes de tal «alteración de la percepción desde el nacimiento..» En este caso, entre otras razones se dice que «la inimputabilidad proviene de una ausencia de socialización derivada de una minusvalía física, no psíquica» (06)(61), o por subdesarrollo cultural, en que la ausencia de educación, junto al desarrollo de la persona en un medio carente de cultura e instrucción, limitarían notoriamente la percepción de la realidad y el conocimiento de la ley.

\section{IMPUTABILIDAD O CULPABILIDAD DISMINUIDA (Capacidad de motivación disminuida)}

La ley penal regula la imputabilidad disminuida o «semimputabilidad», cuando no se dan todas las condiciones para una eximente completa por inculpabilidad. No obstante ha existido una amplia discusión en el campo jurídico penal y psiquiátrico forense, sobre la existencia de la imputabilidad disminuida o la «semi-imputabilidad», entre otras denominaciones creadas por los «científicos» del derecho penal (13) (31) (68). Sin embargo, en el campo de la salud mental no se puede pensar en una dicotomía rígida, entre cuerdo o loco, en sano o "enfermo», lo que no quiere decir que se plantee una tripartición, sino más bien considerar que de acuerdo a las particularidades individuales y la evolución del problema mental, no siempre un psicótico por ejemplo es igual a otro psicótico. Además, según el proceso del trastorno mental, este puede ser «border line», estar en fase inicial o en una etapa aguda, en estado crónico o en remisión, entre otras condiciones, que inciden de diverso modo en su capacidad de comprensión. Asimismo hay trastornos mentales que no originan una limitación total de la capacidad mental, como en los casos de neuróticos, parafílicos, personas con trastornos de personalidad (psicopatías), entre otros; aunque en ciertas personas y casuísticamente, 
algunos de tales síndromes podrían originar una disminución de la imputabilidad.

$\mathrm{Al}$ respecto podemos prever formalmente, de acuerdo a nuestro texto legal, tres casos genéricos de "semi-imputabilidad», aunque por las razones anotadas en el análisis de la inculpabilidad, sólo es aceptable desde nuestro punto de vista, el primer caso:

2.1. Imputabilidad disminuida por anomalía psíquica no incapacitante plenamente. Entre ellas se encuentran diversas formas de trastorno mental que no producen inimputabilidad total. Es así que concordando la primera parte del inciso 1o. del artículo 20, con el artículo 21 del C.P., nos interesa revisar las situaciones en que no se presentan todos los elementos necesarios para la inculpabilidad completa, y que no hacen desaparecer totalmente la responsabilidad del procesado, y puede darse en los siguientes trastornos:

a. Algunas anomalías orgánicas: podemos considerar algunos Trastornos de la personalidad y del comportamiento debido a enfermedades, lesiones o disfunciones cerebrales (F07), cuando tienen relación con algún problema penal, aunque su capacidad de juicio no se halle totalmente alterada, pero si en alguna medida significativa, lo que puede ameritar la imputabilidad disminuida. Sobre todo el Síndrome postencefalítico (F07.1), que de acuerdo al caso concreto y el grado del trastorno, la persona que la padece puede ser considerada con responsabilidad disminuida. Al respecto la OMS dice que las «manifestaciones de este trastorno suelen consistir en malestar general, apatía o irritabilidad, cierto déficit de las funciones cognoscitivas, alteración de los hábitos de sueño y la ingesta, cambios de la conducta sexual y disminución de la capacidad de juicio...» (35). Situación similar puede darse en el caso de conductas delictivas por persona con Síndrome postconmocional (F07.2).

b. Algunos Trastornos mentales y del comportamiento debido al uso de sustancias psicotropas, alcohol y/drogas (F10 a F19). En casos que no ocurran efectos severos por el consumo de dichas sustancias, y que no ocasionen eximencia completa, pueden ser anomalías que produzcan una imputabilidad disminuida, como en la intoxicación aguda no complicada (F10.00 a F19.00) al consumir pequeñas dosis de la sustancia, alcohol o alguna de las diversas drogas, excepto la «ebriedad patológica» (F10.07) que sería causal de eximencia, así como las debidas a los alucinógenos.

c. Trastornos neuróticos (F40 a F48): Sobre todo la Ansiedad fóbica (F40) en sus diversas manifestaciones, como la Agorafobia 
(F40.0); Otros Trastornos de ansiedad (F41), sobre todo el Trastorno de pánico (F41.0); Trastornos obsesivo-compulsivos (F42); igualmente las Reacciones a estrés grave y trastornos de adaptación (F43); asimismo los Trastornos disociativos (de conversión) (F44), de acuerdo a la naturaleza del ilícito cometido y que deben ser valorados en cada caso concreto, si las manifes taciones neuróticas no son muy intensas. En general, en estos trastornos no existe una perdída de comprensión de la persona, incluso algunos pueden desempeñar sus actividades, aunque llenos de ansiedad y algunos otros síntomas neuróticos. Salvo casos especiales que ya revisamos en el rubro de la inimputabilidad, como las fobias, el trastorno de pánico y algunas disociativas.

d. Trastornos específicos de la personalidad (psicopatías). Pueden tener influencia en la imputabilidad relativa algunos de estos trastornos, antes llamados personalidades psicopáticas, que incluyen a más de diez variedades de trastornos. En este tema han existido y aún subsisten criterios dispares, desde algunos que consideran que da lugar a inimputabilidad total, hasta otros que opinan por su plena responsabilidad penal. En estos trastornos, las personas no pierden su capacidad de valoración y comprensión de la realidad, pero las distorsiones «permanentes» de su personalidad pueden jugar un papel importante en los desajustes de su conducta. Al respecto, Langeluddeke (31) señala que la tesis de la imputabilidad disminuida surgió en parte pensando en los casos de los «psicópatas», hoy llamado trastorno de personalidad, sobre todo en los trastornos paranoides (F60.0), trastornos disociales (F60.2), y los trastornos tipo impulsivo (F60.30), entre otros, que según una idea hoy superada se hallaban entre la salud y la enfermedad, por lo que la práctica jurisprudencial ha sido controversial al respecto (67), pero no descartamos que se puede admitir la imputabilidad disminuida, de acuerdo al trastorno específico de personalidad y el ilícito penal concreto.

El trastorno paranoide de la personalidad, presenta «un patrón de desconfianza y suspicacia general hacia los otros, de forma que las intenciones de éstos son interpretadas como maliciosas. Este patrón empieza al principio de la edad adulta». El Trastorno disocial, llamado trastorno antisocial por la DSM norteamericana, se caracteriza por desprecio y violación de los derechos de los demás, que comienza en la infancia o al inicio de la adolescencia y continúa en la edad adulta. La psiquiatría anglosajona del siglo pasado denominó psicopatía a este trastorno particular. Pichot dice que las personas con este trastorno "frecuentemente carecen de empatía y tienden a ser insensibles, cínicos y a menospreciar los sentimientos, derechos y penalidades de 
los demás. Pueden tener un concepto de si mismos engreído y arrogante (pensar que el trabajo normal no está a su altura, o no tener una preocupación realista por sus problemas actuales o futuros) y pueden ser excesivamente tercos, autosuficientes o fanfarrones..» (39). La evolución de este trastorno tiene un desarrollo crónico, pero puede volverse menos manifiesto o remitir, conforme la persona se hace mayor.

e. El «retraso mental leve»: Para diversos autores, la persona que se halla en el nivel de «retardo mental leve» o «debilidad mental» que era la forma menos grave de la «oligofrenia» (denominación usada en el siglo pasado) no sería un inimputable completo sino más bien un inimputable relativo, dado que su capacidad intelectual no tiene un deterioro muy marcado como los casos de «retardo mental moderado», "grave» y "profundo», en los que si se justifica su condición de inimputables. Asimismo, según el caso particular, algunos personas de inteligencia border line o fronterizos, antes llamados «morones», igualmente podrían caer dentro de la imputabilidad disminuida.

f. Otros tipos de «trastorno mental». Pueden tener alguna incidencia en la imputabilidad relativa, considerando el problema delictivo concreto y las circunstancias de su comisión, los casos de personas que por ejemplo sufren de Trastornos de los hábitos y del control de los impulsos (F63), como la «cleptomanía» (F63.2), caracterizado por la dificultad de controlar el impulso de hurtar cualquier objeto, aun cuando no sea necesario para su uso personal o por su valor económico; en este caso la persona es consciente de que se trata de un acto equivocado, y con frecuencia teme ser arrestada. Si el cleptómano se ve involucrado en un delito de hurto, su trastorno mental puede tener importancia según las circunstancias para este caso concreto, y podría argumentarse imputabilidad disminuida o eximencia en caso extremo muy particular; pero si cometiese un homicidio, no podría alegar dicho trastorno mental para fundamentar su imputabilidad relativa, menos eximencia. Por ello no estamos de acuerdo con Joaquim Homs Sanz (26), quien argumenta que en caso de hurto el cleptómano debe ser en todos los casos inimputable. Este trastorno se diferencia de los actos ordinarios de robo o sustracción de pequeños objetos en tiendas, que está motivado por la utilidad del objeto o por su valor económico. Además la cleptomanía es una alteración mental rara, poco frecuente. También pueden tener alguna relación con la disminución de la responsabilidad penal, los casos de ludopatía (F63.0), piromanía (F63.1), según que las circunstancias del hecho delictivo. 
2.2. Imputabilidad disminuida por "grave alteración de la conciencia» y por alteraciones de la percepción incompletas. Como hemos sostenido a lo largo de este artículo, los casos antes llamados grave alteración de la conciencia, son variedades de anomalías psíquicas, por ello de acuerdo a lo revisado en el punto anterior no tiene sentido redundar en este rubro. Más bien si es factible que personas con problemas de discapacidad sensorial, como los sordos (mudos), ciegos, y ciego sordos, sin estar en una situación de incapacidad plena para darse a entender, en el caso de una comisión delictiva podrían ser considerados con responsabilidad penal disminuida.

\section{REFERENCIAS BIBLIOGRÁFICAS}

01. AGUDELO, Nódier. Los «inimputables», Frente a las Causales de Justificación e Inculpabilidad, Bogotá: Editorial Temis, 1986.

02. AMUCHATEGUI, Irma. Derecho Penal, México: Editorial Harla,1993.

03. BACIGALUPO, Enrique. Manual de Derecho Penal, Parte General Bogotá: Editorial Temis, 1989.

04. BACIGALUPO, Enrique. Lineamientos de la Teoría del Delito,

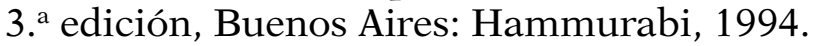

05. BACIGALUPO, Enrique. Derecho Penal. Parte General, Lima: Ara Editores. 2004.

06. BERDUGO, Ignacio y Otros. Lecciones de Derecho Penal.Parte general, 2. ${ }^{\text {a }}$ edición, Barcelona: La Ley, 1999.

07. BOLLES, Robert. Teoría de la motivación, México: Editorial Trillas, 1973.

08. BONNET, Emilio. «El trastorno mental transitorio», en Criminalia, México, 1964, N. ${ }^{\circ} 4$.

09. BONNET, Emilio. Psicopatología y psiquiatría forenses, Tomo I, Buenos Aires: López Libreros Editores, 1983.

10. BRAMONT-ARIAS T., Luis A. y María del Carmen GARCÍA. Manual de derecho penal. Parte especial, 4. ${ }^{a}$ edición, Lima: 1998.

11. BRAMONT-ARIAS T., Luis M. Manual de derecho penal. Parte general, 2. ${ }^{a}$ edición, Lima: EDDILI, 2002.

12. CABELLO, Vicente. Psiquiatría forense en el derecho penal, Tomo I, Buenos Aires: Editorial Hammurabi, 1981. 
13. CABELLO, Vicente. Psiquiatría forense en el derecho penal, Tomo II, Buenos Buenos Aires: Editorial Hammurabi, 1982.

14. CEREZO MIR, José. «El delito como acción culpable», en ROMEO, Carlos (Ed.). Dogmática penal, política criminal y criminología en evolución, Tenerife-Canarias: Editorial Comares, 1977.

15. CIAFARDO, Roberto. Psicopatología forense, Buenos Aires: El Ateneo, 1973.

16. COBO DEL ROSAL, M. y T. S. VIVES ANTÓN. Derecho penal. parte general, 3. a edición, Valencia: Tirant lo Blanch, 1990.

17. COFER y APPLEY. Psicología de la motivación, México: Editorial Trillas, 1971.

18. DELGADO, Honorio. Curso de psiquiatría, Barcelona, Editorial Cientifico-Médica, 1963.

19. DOVAL, Antonio. «Las consecuencias jurídico-penales de la enajenación mental y el Trastorno Mental Transitorio. Perspectiva Histórica», Cuaderno de Política Criminal, Madrid, 1989, N. 39.

20. FERREIRA, Francisco. Teoría general del delito, Bogotá: Temis, 1988.

21. FREEDMAN, Alfred y otros. Compendio de psiquiatría, Barcelona: Salvat Editores, 1978.

22. FRÍAS C., Jorge. Imputabilidad Penal, Buenos Aires: Ediar, 1981.

23. GALGUERA, Isabel y otros. El Retardo en el desarrollo, México: Editorial Trillas, 1984.

24. HENRÍQUEZ, Enrique. «Factores patológicos y criterios de peligrosidad en el trastorno mental transitorio médico-legal», en Criminalia, México: 1955, N. ${ }^{\circ} 7$.

25. HOMS SANZ DE LA GARZA, Joaquim.Trastorno mental transitorio y drogas que inciden en la imputabilidad, Barcelona: José M. ${ }^{\mathrm{a}}$ Bosch Editor, 1996.

26. HOMS SANZ DE LA GARZA, Joaquim. Avances en medicina legal: Ingeniería genética, alteraciones psíquicas y drogas, Barcelona: José M. ${ }^{a}$ Bosch Editor, 1999.

27. HURTADO POZO, José. Manual de derecho penal. Parte general I, Lima: Grijley, 2005.

28. IRRISARI, Carlos. «Inimputabilidad penal. La evolución en el tratamiento de las psicopatías», Revista Debate Penal, Lima, 1989, N. ${ }^{\text {os }} 7-8-9$. 
29. JAKOBS, Günther. Derecho penal. Parte general, 2. a edición, Madrid: Marcial Pons, 1997.

30. JIMÉNEZ DE ASUA, Luis. La ley y el delito, Buenos Aires: Editorial Hermes, 1959.

31. LANGELUDDEKE, Albrecht. Psiquiatría forense, Madrid: Espasa Calpe, 1972.

32. MIR PUIG, Santiago. Función de la pena y teoría del delito en el estado social y democrático de derecho, Barcelona: Editorial Bosch, 1982.

33. MIR PUIG, Santiago. Derecho penal. Parte general, $5 .^{a}$ edición, Barcelona: Tecfoto, 1999.

34. NAQUIRA, Jaime. «Debilidad mental e inimputabilidad penal» en Derecho Penal, Homenaje a Raúl Peña, Lima: Ed. Jurídicas, 1991.

35. OMS. CIE 10. Trastornos mentales y del comportamiento. descripciones clínicas y pautas para el diagnóstico, Madrid: Meditor, 1992.

36. ORGANIZACIÓN MUNDIAL DE SALUD. Clasificación internacional de enfermedades, Vol. 1, Washington: 1978.

37. PEÑA, Raúl. Tratado de derecho penal. Estudio programático de la parte general, Lima: Editorial Grijley, 1994.

38. PEREZ, Luis Carlos. «Imputabilidad e inimputabilidad», en Derecho Penal y Criminología, Bogotá: 1980, N. ${ }^{\circ} 12$.

39. PICHOT, Pierre (Coord.). DSM IV. Manual diagnóstico y estadístico de los trastornos mentales, Barcelona: Masson, 1995.

40. POLAINO NAVARRETE, Miguel. Instituciones de derecho penal.Parte general, Lima: Grijley, 2005.

41. PRADO, Víctor. Comentarios al código penal de 1991, Lima: Editorial Alternativas, 1993.

42. RAGUES I VALLES, Ramón. El dolo y su prueba en el proceso penal, Barcelona: J. M. Bosch Editor, 1999.

43. REYES, Alfonso. Imputabilidad, Bogotá: Editorial Temis, 4ta. edición 1989.

44. RIGHI, Esteban. La culpabilidad en materia penal, Buenos Aires: Ad Hoc, 2003.

45. ROXIN, Claus. Derecho penal. Parte general, Tomo I, Madrid: Editorial Civitas, 1997. 
46. SÁNCHEZ-VERA, Javier. Atribuciones normativistas en el derecho penal, Lima: Grijley, 2004.

47. SCHNEIDER, Kurt. Patopsicología clínica, Madrid: Editorial Paz Montalvo, 1963.

48. SCHNEIDER, Kurt. Las personalidades psicopáticas, Madrid: Ediciones Morata, 1965.

49. SERPA, Roberto. Tratado de psiquiatría forense, Bogotá: Editorial Temis, 1979.

50. SERPA, Roberto. "Peritación psiquiátrica e inimputabilidad», Derecho Penal y Criminología, Bogotá, 1982, N. ${ }^{\circ} 1$.

51. SERPA, Roberto. Psiquiatría médica y jurídica, Santa Fé de Bogotá: Editorial Temis, 1994.

52. SERRANO MAILLO, Alfonso. Introducción a la Criminología, Lima: Ara Editores, 2004.

53. SILVA, Hernán. Diccionario de psiquiatría forense, Santiago de Chile: Editorial Jurídica de Chile, 1988.

54. SOLÍS E., Alejandro. «Aspectos psicopatológicos de la inimputabilidad», Revista Peruana de Ciencias Penales, Lima, 1994, N. ${ }^{\circ} 4$.

55. SOLÍS E., Alejandro. Ciencia penitenciaria y derecho de ejecución pena 5. a edición, Lima: Editorial FECAT, 1999.

56. SOLÍS E., Alejandro. Metodología de la investigación jurídico social, 2. ${ }^{a}$ edición, Lima: Editorial FECAT, 2001.

57. SOLÍS E., Alejandro. Criminología: Panorama contemporáneo,

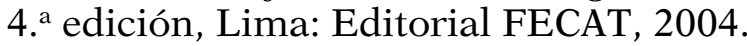

58. SOLORZANO, Roberto. Psiquiatría clínica y forense, Bogotá: Editorial Temis, 1990.

59. SURIA, M. ${ }^{a}$ D. Guía Para padres de niños sordos, Barcelona: Imp. Hogar, 1974.

60. TAMARIT, Joseph. «Política criminal con bases empíricas en España», Política Criminal, N. ${ }^{\circ} 3$, 2007. (http://www.politicacriminal.cl).

61. TERRADILLOS, Juan. "Culpabilidad-Responsabilidad», Anuario de Derecho Penal, Lima, 2003.

62. TIEGHI, Osvaldo. Tratado de criminología, Buenos Aires: Editorial Universidad 1989.

63. VILLAVICENCIO T., Felipe. Derecho penal. Parte general, Lima: Grijley, 2006. 
64. WEYGANDT, W. Psiquiatría forense, Barcelona: Editorial Labor, 1928.

65. WOODRUFF, Robert y otros. El Diagnóstico en psiquiatría, México: Editorial El Manual Moderno, 1978.

66. WORLD HEALTH ORGANIZATION. International statistical classification of diseases and related health problems, Vol. 1 (Tenth revision), Geneva: 1992.

67. YAÑEZ, Pedro. "Consideraciones en torno a la «Imputabilidad disminuida» con especial referencia a los Psicópatas. Su Tratamiento y los denominados «Establecimientos de terapéutica Social», en Anuario de Derecho Penal y Ciencias Penales, Madrid, 1970, T.XXII, Fasc. II.

68. ZAFFARONI, Eugenio. Tratado de derecho penal, Vol. IV, Buenos Aires: Ediar, 1982.

69. ZAFFARONI, Eugenio. Manual de derecho penal, Parte general, Lima: Ediciones Jurídicas, 1994.

70. ZAFFARONI, Eugenio y Alejandro ALAGIA y A. SLOKAR. Manual de derecho penal. Parte general, Buenos Aires: Ediar, 2005. 